\title{
EDUCAÇÃO FÍSICA ESCOLAR, CORPO E SAÚDE NO CONTEXTO DO ENSINO MÉDIO
}

\author{
Juliana Rocha Adelino Dias ${ }^{\text {D1 } 1}$ e Rogério Cruz de Oliveira iD2
}

\section{Resumo}

A presente pesquisa teve como objetivo compreender a abordagem da temática corpo e saúde nas aulas de Educação Física (EF) observando a organização e desenvolvimento dessa temática pelo professor. Trata-se de um estudo qualitativo que encontra na etnografia o seu referencial metodológico. Para o desenvolvimento do estudo foi utilizado como instrumento de coleta de dados a observação participante, com o uso de um roteiro de observação das aulas de Educação Física que contemplou os atores escolares envolvidos e o tema pesquisado. $O$ instrumento escolhido foi utilizado por sua possível harmonização com o estudo realizado em âmbito escolar $O$ estudo contou com a participação de 26 alunos e um professor de Educação Física de uma escola estadual do ensino médio da cidade de Santos-SP. Os dados coletados foram tratados à luz da análise de conteúdo. Nesse estudo, foi possível perceber a existência de uma divisão entre aula teórica e prática, sendo que as aulas práticas priorizam o esporte, enquanto que as aulas teóricas apresentam o tema saúde em uma perspectiva fundamentada nos aspectos biológicos. Por isso, ressaltamos a necessidade de se reinterpretar o cenário composto pela EF e o tema saúde. Nesse sentido, pensamos na possibilidade de se aprofundar na escola os temas existentes e abordados nas aulas de EF, mas considerando e fundamentado a saúde sob a ótica de um conceito ampliado que considere o ser humano no todo, inclusive, em seu contexto social.

Palavras-chave: Cultura Corporal; Educação Escolar; Prática Pedagógica.

\section{SCHOOL PHYSICAL EDUCATION, BODY AND HEALTH IN THE CONTEXT OF HIGH SCHOOL}

\section{Abstract}

The present research aims to understand the approach of the theme body and health in School Physical Education (PE), observing the organization and development of this theme by the teacher. It is a qualitative study that finds its methodological framework in ethnography. For the development of the study, participant observation was used as a data collection instrument, with the use of an observation script for Physical Education classes that included the school actors involved and the researched theme. The chosen instrument was used due

${ }^{1}$ Doutora em Ciências da Saúde pela Universidade Federal de São Paulo Campus Baixada Santista. Professora da Rede Estadual de Educação de São Paulo e da Rede Municipal de Educação de Cubatão-SP.

${ }^{2}$ Doutor em Educação Física. Professor do curso de Educação Física e do Programa de Pós-graduação Interdisciplinar em Ciências da Saúde da Universidade Federal de São Paulo - Campus Baixada Santista. Departamento de Ciências do Movimento Humano. Líder do Grupo de Estudo e Pesquisa Sociocultural em Educação Física (GEPSEF/UNIFESP).

Perspectivas em Diálogo, Naviraí, v. 08, n. 17, p. 528-546, maio./ago. 2021. 
to its possible harmonization with the study carried out at school environment. The study had the participation of 26 students and a Physical Education teacher from a state high school in the city of Santos-SP. The collected data were treated in the light of content analysis. In this study, it was possible to notice the existence of a division between theoretical and practical classes, with practical classes prioritizing sport, while theoretical classes present the health theme in a perspective based on biological aspects. Therefore, we emphasize the need to reinterpret the scenario composed by $\mathrm{PE}$ and the health theme. In this sense, we think about the possibility of deepening in school the existing themes and addressed in PE classes, but considering and grounding health from the perspective of an expanded concept that considers the human being as a whole, including in their social context.

Keywords: Body Cultural; Education; Pedagogical Practice.

\section{Introdução}

No âmbito educacional, a Educação Física (EF) representa uma das disciplinas dedicadas a promover a compreensão sobre valores e significados que estão implícitos nas práticas corporais presentes na sociedade (SILVA; SILVA; LÜDORF, 2015). Porém, cabe ressaltar que esta disciplina teve em sua origem o objetivo de atuar na formação integral do aluno, com a inclusão do eixo corpo na educação formal. Contudo, essa inclusão fortaleceu a concepção fragmentada do ser humano em corpo, mente e espírito, acrescentando, portanto, no contexto escolar a educação do corpo as já existentes educação moral e intelectual (BETTI; ZULIANI, 2002). Desse modo, a EF desponta no cenário da educação nacional como responsável pela concepção de corpos saudáveis e dóceis, e para obter sucesso nessa construção esteia-se na justificativa da necessidade e vantagem de intervir sobre o corpo segundo uma ordem médico-científica (BRACHT, 1999).

Nessa intervenção destinada a educação dos corpos, a instituição militar e a medicina tiveram papéis de destaque. A instituição militar realizava a prática com exercícios sistematizados e ressignificados a luz do conhecimento médico, tais intervenções aconteciam de maneira a ultrapassar o limiar do terapêutico, tornando-se, assim, uma ação, principalmente, do campo pedagógico (BRACHT, 1999). Por isso, desde meados do século XIX, é possível perceber a aproximação entre a educação física e a saúde, essa aproximação se justifica pela atribuição delegada as atividades físicas como forma de fortalecer a saúde dos brasileiros e das brasileiras (GOELLNER, 2010). Neste cenário, a educação dos corpos para o desenvolvimento e manutenção da saúde legitima a EF e esta passa a ter seu espaço, pois o ideal de educar o corpo "[...] significa promover saúde e educação para a saúde (hábitos saudáveis, higiênicos). Essa saúde ou virilidade (força) também pode ser (e foi) ressignificada numa perspectiva nacionalista/patriótica" (BRACHT, 1999, p. 73).

Portanto, a EF se consolida na história de maneira a validar os princípios nacionalistas que direcionavam suas práticas a "[...] um projeto de humanidade centrado na eliminação de tudo aquilo corporalmente intolerável" (GOELLNER, 
2010, p. 528). Embora, assintamos que estes foram ideais do passado pode-se dizer que ainda reverberam vestígios no presente momento, conforme é relatado a seguir:

A articulação entre saberes pedagógicos e médicos sustentou a estruturação da educação física brasileira e, de outros modos, ainda a sustenta na atualidade. No início do século XX, com base em preceitos higiênicos e eugênicos, incentivavam-se as atividades físicas objetivando a melhoria das capacidades orgânicas dos indivíduos. Hoje, outras são as representações ligadas a essas práticas. Aptidão física, performance, qualidade de vida, estética, boa forma, vida saudável são exemplos de expressões frequentes em diversos discursos que circulam em distintos espaços sociais (GOELLNER, 2010, p. 529).

No entanto, percebe-se que a EF na escola vai além de uma intervenção corporal embasada em orientações médicas ou aperfeiçoamento das capacidades orgânicas. Embora, na EF o corpo, factualmente, tenha sido encarado numa perspectiva que o coloca em uma condição de propriedade biológica da humanidade o que justificaria os benefícios nas intervenções nas esferas física e biológica (DAOLIO, 2016, p. 62). Por isso, é indispensável levar em conta que a EF tem o propósito de "[...] integrar e introduzir o aluno de $1^{\circ}$ e $2^{\circ}$ graus no mundo da cultura física, formando o cidadão que vai usufruir, partilhar, produzir, reproduzir e transformar as formas culturais da atividade física (o jogo, o esporte, a dança, a ginástica" (BETTI, 1992, p. 285). Deste modo, é possível constatar que o papel desta disciplina ultrapassa o ensinar os saberes que compõem a cultura corporal do movimento. A esse respeito, percebe-se a corroboração da Base Nacional Comum Curricular (BNCC) para o ensino médio. Nela, os conteúdos da EF contemplam a necessidade de atuação de modo que o aluno a partir da compreensão, da apreciação e da produção dos conhecimentos que são próprios da disciplina, possa reconhecer com propriedade o mundo ao seu redor (BRASIL, 2018). A esse respeito, o documento declara que os alunos do ensino médio acerca das práticas da EF devem perceber as possibilidades de:

[...] modos de viver e perceber o mundo a elas subjacentes; ao compartilhamento de valores, condutas e emoções nelas expressos; à percepção das marcas identitárias e à desconstrução de preconceitos e estereótipos nelas presentes; e, também, à reflexão crítica a respeito das relações práticas corporais, mídia e consumo, como também quanto a padrões de beleza, exercício, desempenho físico e saúde (BRASIL, 2018, p. 483).

Por isso, a premência de se pensar que a EF pode abordar na escola questões que estão imbricadas na sociedade contemporânea e que possuem espaço de destaque na vida dos estudantes, dentre essas questões destacamos temas relacionados a saúde, tais como, atividade física, cuidados corporais, estética e concepção de beleza. Pois, como lembra Carrano (2011), é necessário considerar a questão do corpo no processo educativo, e colocar esse quesito no 
centro deste sistema. Com a intenção de oportunizar aos alunos reflexões que também envolvam o padrão corporal que é divulgado atualmente e o seu próprio corpo (DIAS, 2013).

Nesse interim, enxergamos o corpo em uma perspectiva cultural em suas nuances políticas e sociais, algo que vai além da condição física/biológica. Com isso, entendemos que o corpo pode ser percebido enquanto impressão do meio em que o indivíduo está inserido, em suas marcas culturais e sentido. Ele, o corpo, reverbera por meio dos comportamentos, acessórios e vestimenta, seu modo de ser, os costumes de um grupo ou de uma determinada população (GOELLNER, 2007). No corpo são traduzidas as características e costumes de uma sociedade. Nesse sentido, como nos alerta Daolio (1995), o ser humano (In) Corpora, traz para o seu corpo as expressões culturais em suas normas, valores e costumes.

Logo, reiteramos o exposto por Lüdorf (2009), quando a autora afirma que o professor de EF, em sua prática cotidiana, pode contribuir para a formação de valores de ordem socioculturais, subjetivos e políticos. Logo, as aulas de EF, como uma disciplina integrante do currículo escolar, pode proporcionar um sentido que vai além de seu caráter dinâmico e lúdico, nessas aulas é possível se fomentar um ambiente favorável para a formação crítica do aluno em seu processo de aprendizado, de conscientização e de aquisição de conhecimentos e experiências para a vida, respeitando, por exemplo, as diferenças, o próprio corpo e o corpo do outro (GONÇALVES; AZEVEDO, 2007).

Isto posto, é importante lembrar a ênfase atribuída aos aspectos biológicos e físicos quando se traz o assunto corpo e saúde para as aulas de Educação Física, como aborda Devide (2007) ao afirmar que atualmente existe uma relação vista como direta entre o exercício físico e a promoção de saúde, desconsiderando assim, os diversos elementos ambientais envolvidos e presentes na questão da saúde. Embora seja notório os benefícios de uma vida com hábitos considerados saudáveis, dentre eles, a prática de atividade física, não se pode deixar de se contextualizar os aspectos históricos e culturais que, também, influenciam nesse cenário. Por isso, acerca da concepção ampliada em saúde na área da EF ressaltamos, como o apontado por Oliveira, Gomes e Bracht (2014) que:

Mesmo que seja realizada uma "crítica" (no âmbito do discurso) à concepção restrita de saúde, se isso não tiver um impacto inovador nas práticas pedagógicas cotidianas não será capaz de afetar a agenda estabelecida pela representação hegemônica da concepção de saúde construída no seio da EF - que orienta a construção de discursos e práticas. Compreendemos que a crítica deve ser seguida das práticas inovadoras (e vice-versa), uma vez que ambas devem estar presentes na mudança dos cenários em que as concepções e práticas de saúde são construídas. (OLIVEIRA; GOMES; BRACHT, 2014, p. 70).

Assim sendo, destaca-se que, apesar de constar no currículo do estado de São Paulo do ensino médio na disciplina de Educação Física, variados temas que são caros ao entendimento da saúde, e estes no caderno do aluno, material impresso recebido semestralmente pelos os estudantes da rede, estes, muitas 
vezes, são externados em uma perspectiva reduzida as questões biológicas. Isto posto, percebe-se que não é contemplado o conceito ampliado de saúde que possui enfoque holista e que considera as condições de trabalho, as oportunidades de lazer, a alimentação e as condições de vida como um todo (MINAYO, 1997).

Dadas as preocupações elencadas acima, o presente estudo problematiza: Quais aspectos relacionados ao corpo e a saúde são abordados nas aulas de EF no ensino médio? Frente ao exposto, os objetivos consistem em: Compreender a abordagem da temática corpo e saúde nas aulas de EF; e Observar a organização e desenvolvimento dessa temática pelo professor de EF em suas aulas.

Esse estudo justifica-se pela oportunidade de ampliar o debate sobre as relações entre a EF e a saúde, marcada historicamente, por um discurso hegemônico de causa e efeito, com a ampla apresentação de uma ideia em que a prática da atividade física gera saúde.

\section{Metodologia}

A pesquisa apresenta uma abordagem qualitativa (GOLDENBERG, 2007) e encontra na etnografia o seu referencial metodológico. Contudo, torna-se necessário salientar, como nos lembram Oliveira e Daolio (2007), que realizar um estudo etnográfico transcende a questão da escolha dos instrumentos, ele está intimamente ligado à como os dados coletados são percebidos, analisados e correlacionados. Para isso, a coleta de dados da pesquisa aconteceu em seu ambiente natural de modo a propiciar a exploração dos comportamentos, bem como a comunicação entre os indivíduos em suas singularidades para a compreensão da dinâmica do grupo estudado.

Participaram do estudo 26 alunos do ensino médio, todos devidamente matriculados numa turma de $1^{0}$ ano do ensino médio de uma escola pública estadual localizada na cidade de Santos SP e o professor de EF dessa mesma turma. Os voluntários foram de ambos os sexos e com faixa etária acima de 14 anos. Todos os participantes do estudo foram identificados por pseudônimos com o propósito de manter o anonimato.

Foram adotados os seguintes critérios de inclusão: Ser professor efetivo há, no mínimo, 2 anos na rede estadual de educação de São Paulo; e ser aluno há, no mínimo, 2 anos da rede estadual. Tais critérios justificam-se pela maior e melhor familiarização de professores e alunos com o currículo paulista desenvolvido por meio de material didático pedagógico distribuído às escolas.

Para participação no estudo, o professor de EF e os responsáveis assinaram um Termo de Consentimento Livre e Esclarecido (TCLE), bem como os alunos assinaram um Termo de Assentimento. Os nomes de alunos citados nesse texto tratam-se de pseudônimos. Este estudo foi aprovado pelo Comitê de Ética e Pesquisa da Universidade Federal de São Paulo sob CAAE no 63684216.0.0000.5505.

Nesse estudo, a escola e as aulas de EF foram pensadas como campo de estudo, como um modelo nativo, com uma "[...] referência espacial, a presença de regular de seus membros, e um código de reconhecimento e comunicação 
entre eles" (MAGNANI, 2002, p.20). Assim, como abordado por Magnani (2002), com um olhar de perto e de dentro do contexto escolar e das aulas de EF entendemos a necessidade em realizar uma ampla observação da cultura e da vida social na busca de traduzir o fenômeno estudado e ter acesso as atitudes, valores, crenças, hábitos e modos de vida dos pesquisados (GEERTZ, 1989).

Para viabilizar a investigação, o instrumento de coleta de dados consistiu na observação participante, com o uso de um roteiro de observação das aulas de EF que contemplou os atores escolares envolvidos e o tema pesquisado. $O$ diário de campo foi utilizado como recurso de registro das observações. 0 conjunto de estratégias presentes na observação participante, conforme nos apresentou Moreira (2002), pode ser ilustrado na ida do pesquisador à campo, quando este experimenta na prática o fenômeno social a ser estudado para melhor entendê-lo, percebendo e agindo de acordo com as suas interpretações daquele contexto, observando como as relações sociais estabelecidas no campo permitem entender as ações acompanhadas. Portanto, entende-se que no ambiente natural do estudo, é possível perceber os voluntários agirem e exprimirem sentido e significado em relação aos acontecimentos explorados.

Assim, na observação participante o pesquisador deve se tornar parte do universo investigado para melhor entender as ações daqueles que ocupam e produzem culturas, apreender seus aspectos simbólicos, que incluem costumes e linguagem. Na observação participante, o observador torna-se parte da situação a observar. O pesquisador parte das observações do comportamento verbal e não verbal dos participantes, de seu meio ambiente, das anotações feitas quando presente no campo (MOREIRA, 2002).

Esse instrumento (a observação participante) foi adotado por sua possível harmonização com o estudo realizado em âmbito escolar. Neste caso, refere-se a identificação e compreensão de como é concebido pelos atores escolares as questões referentes a EF no ensino médio, corpo e saúde a partir de seus significados culturais. Para isso, foi utilizado o seguinte roteiro: 1)observação das atividades realizadas baseadas na temática corpo-saúde; 2) observação da reação dos alunos às atividades propostas; e 3) observação do método e/ou estratégias de abordagem do tema. .

As observações tiveram início em março de 2018, foram suspensas no mês de julho, período de férias escolares, retornaram em agosto do mesmo ano e foram finalizadas no em setembro de 2018, totalizando aproximadamente 7 meses de inserção na escola. Neste período, a escola foi visitada em 20 ocasiões, a saber: 15 dias para acompanhar as aulas de EF (um total de 30 aulas) e 5 dias para conviver com outras atividades escolares como reuniões de pais, ensaio para a festa junina, organização da Festa das Nações e acompanhamento de um jogo de futsal em que alguns alunos da turma observada e de outras turmas da mesma escola participaram nos jogos escolares em seletiva regional.

Para a análise dos dados consideramos um "[...] olhar multifacetado sobre a totalidade dos dados recolhidos no período da coleta" (CAMPOS, 2004, p. 611). Com a finalidade de conhecer em profundidade o objeto investigado foi utilizado a análise de conteúdo, com esta técnica buscou-se acessar os sentidos atribuídos pelos sujeitos investigados. Por isso, o material produzido nas observações foi submetido à análise de conteúdo proposta por Bardin (1977). 
Esta analise prevê três etapas principais, que são: $1^{a}$ ) Pré-análise - que trata do esquema de trabalho, envolve os primeiros contatos com os documentos de análise, a formulação de objetivos, a definição dos procedimentos a serem seguidos e a preparação formal do material; 2a) Exploração do material - que corresponde ao cumprimento das decisões anteriormente tomadas, isto é, leitura de documentos e categorizações; e que esta etapa de interpretação deve ir além dos conteúdos manifestos no instrumento, buscando descobrir o que está por trás do imediatamente apreendido. Com esses procedimentos, pretendeuse responder às questões de estudo de forma sistemática, com uma melhor compreensão das falas e observações a partir das construções culturais dos voluntários da pesquisa. Cabe salientar que o artigo é fruto de tese de doutorado em desenvolvimento.

\section{Resultados e discussões}

Durante a pesquisa de campo, a dinâmica das aulas foi bem definida, a primeira aula do bloco era desenvolvida na sala de aula, com exposição teórica do conteúdo. Enquanto que a segunda aula era desenvolvida na quadra com atividades corporais. A exposição teórica era desenvolvida com base no material didático, caderno do aluno, fornecido pelo governo de SP. Foi possível observar que, nesses momentos, os assuntos tratados nas aulas teóricas eram, habitualmente, relacionados a saúde, conforme o material entregue pela Secretaria de Educação, sendo estes complementados por material planejado e estudado pela professora da turma. Durante o período de acompanhamento das aulas para observação foram trabalhados dois temas existentes no currículo do $1^{0}$ ano do ensino médio, a saber: 10) Tema 2 - Corpo, saúde e beleza Conceitos: Atividade física, exercício físico e saúde; e 20) Tema 3 - Ginástica: práticas contemporâneas - Ginástica aeróbica (Durante o período de observação, este foi o único assunto tratado nas aulas teóricas de EF que não possuiu relação direta com a temática saúde). No entanto, a maior parte das aulas realizadas em sala e destinadas aos assuntos teóricos foram destinadas ao Tema 2 da apostila, no total de nove aulas destinadas ao tema Corpo, saúde e beleza, enquanto que ao tema Ginástica, apenas, uma aula tratou o assunto.

Já as aulas práticas correspondem a ida para a quadra, estas aconteceram conforme a possibilidade do dia e, regularmente, tendo como conteúdo predominante os esportes. Algumas vezes as aulas destinadas a prática precisaram ser modificadas por fatores como chuva ou mesmo alagamento dos espaços em que as atividades aconteciam as práticas esportivas. Nessas aulas práticas predominou o que Oliveira e Daolio (2014) denominaram de aula livre. Conforme os autores, nesse modelo de aula o professor disponibiliza o material esportivo, controla o tempo de aula e comportamento dos alunos. Essa dinâmica foi alterada poucas vezes, como nos finais de bimestre, quando a professora os deixou livres para realizar as atividades desejadas, fossem elas atividades esportivas na quadra ou terminando trabalhos e apostilas de outras disciplinas. Ou, quando não tiveram direito a aula prática por estarem de "castigo" por atrapalharem o andamento das aulas de EF e, principalmente, as aulas de outras disciplinas. 
A professora de EF em diversos inícios de aulas observadas adotou o discurso "que se não tiverem bom comportamento com ela e com os outros professores ficariam sem direito de irem para a quadra". Esse discurso é uma fala frequente, assim como já afirmaram Paula, Paixão e Oliveira (2015, p. 463), ao relatarem que é "[...] comum se ouvir nas salas de aula por professores regentes e/ou de outras disciplinas frases como '[...] Ou vocês ficam quietos ou não vão participar da aula de Educação Física'"'. Contudo, a professora se mostrou insatisfeita com o pedido da equipe gestora, acontecido em outrora, de manter os alunos em sala de aula. Em uma conversa no início de um dia letivo, ela mencionou que não manteria aluno em sala por questões que não the competem. Para ela, assim como na sua disciplina, nas outras matérias os professores devem colocar suas regras de conduta, seguindo as normas que estão presentes no estatuto da escola.

As regras a serem seguidas estão postas no estatuto da escola, no entanto, a punição para a quebra dessas regras não é clara, mas, também, em momento algum apontam para suspensão das aulas de EF ou sua modificação para punir o aluno. Tal movimento, parece ser justificado com a prerrogativa de tirar do aluno algo que eles gostam de fazer. Portanto, compreende-se que na escola estão presentes os princípios de vigiar, controlar, corrigir e construir os corpos dos alunos (LOURO, 2000). Neste caso, privando-os, algumas vezes do momento no qual é aguardado e desejado por eles, como relatou o aluno a seguir durante um dia de observação: "[...] ficamos todos os dias aqui sentados e no dia que a gente pensa que vai poder ficar de boa e jogar um fut com os parça, a senhora vem com essa" (ALUNO MATHEUS).

Entretanto, percebe-se que as reclamações dos alunos são fundamentadas sob a perspectiva de não ter o momento livre, o momento de descontração, de jogar bola com os amigos. Assim como, para a inspetora de alunos o momento da aula de EF trata-se apenas de jogar bola. Ambos, não evocam os conteúdos que fazem parte da disciplina para justificar o porquê de ter ou não a aula. A falta da compreensão sobre o papel da EF nas escolas brasileiras é uma realidade, mesmo sendo esta uma disciplina integrante do currículo escolar (CORREIA, 2011). Essa falta de compreensão, provavelmente, conduz o olhar em âmbito escolar e, por vezes, seja o guia das práticas existentes, gerando uma expectativa reduzida ou não condizente com a atual legislação ou, com os documentos que a orientam na educação básica.

No Quadro 1 é possível observar um resumo com o assunto e tipo de aula desenvolvido. 


\section{Quadro 1: Apresentação e breve descrição das aulas de Educação} observadas.

\begin{tabular}{|c|c|c|}
\hline AULA & CONTEÚDOS & $\begin{array}{l}\text { TIPO DE } \\
\text { AULA }\end{array}$ \\
\hline 1 & Apresentação do Tema Corpo, saúde e beleza. & Teórica \\
\hline 2 & $\begin{array}{c}\text { Alongamento, automassagem, jogos fundamentados no } \\
\text { basquete. }\end{array}$ & Prática \\
\hline 3 & O consumo de sódio e açúcar. & Teórica \\
\hline 4 & Alongamento, automassagem, atividades esportivas livres. & Prática \\
\hline 5 & \multirow{2}{*}{ Alongamento em duplas e atividades esportivas livres. } & \multirow{2}{*}{ Prática } \\
\hline 6 & & \\
\hline 7 & Índice de massa corporal (IMC). & Teórica \\
\hline 8 & Atividades esportivas livres. & Prática \\
\hline 9 & $\begin{array}{c}\text { Revisão dos assuntos: IMC e composição dos alimentos } \\
\text { industrializados. }\end{array}$ & Teórica \\
\hline 10 & Circuito e atividades esportivas livres & Prática \\
\hline 11 & $\begin{array}{l}\text { Redação e apresentação do texto sobre o açúcar e o sal na } \\
\text { alimentação. }\end{array}$ & Teórica \\
\hline 12 & $\begin{array}{l}\text { Atividades esportivas livres (para os que apresentaram o } \\
\text { texto da aula anterior); redação para os demais. }\end{array}$ & $\begin{array}{l}\text { Prática/ } \\
\text { Teórica }\end{array}$ \\
\hline 13 & Distúrbios alimentares. & Teórica \\
\hline 14 & $\begin{array}{l}\text { Alongamento, massagem em duplas, atividade esportiva } \\
\text { livres. }\end{array}$ & Prática \\
\hline 15 & Apresentação do tema 3: Atividade rítmica. & Teórica \\
\hline 16 & $\begin{array}{c}\text { Movimentos básicos da ginástica e atividades esportivas } \\
\text { livres. }\end{array}$ & Prática \\
\hline 17 & Atividades da semana do Brincar. & Prática \\
\hline 18 & Atividades esportivas livres. & Prática \\
\hline 19 & Corpo, saúde e beleza em diferentes momentos históricos. & Teórica \\
\hline 20 & Alongamento e jogos fundamentados no vôlei. & Prática \\
\hline 21 & Padrão de beleza e a mídia. & Teórica \\
\hline 22 & Atividades esportivas livres. & Prática \\
\hline 23 & $\begin{array}{l}\text { Atividade física, exercício físico e saúde. Aferição da } \\
\text { Frequência cardíaca. }\end{array}$ & Teórica \\
\hline 24 & $\begin{array}{l}\text { Pular corda, jogos de futsal, vôlei, tênis de mesa e } \\
\text { basquete. }\end{array}$ & $\begin{array}{l}\text { Teórica/ } \\
\text { Prática }\end{array}$ \\
\hline 25 & Organização dos jogos intercalasses. & Teórica \\
\hline 26 & Atividades esportivas livres. & Prática \\
\hline 27 & \multirow{2}{*}{ Atividades esportivas livres. } & \multirow{2}{*}{$\begin{array}{l}\text { Prática/ } \\
\text { Teórica }\end{array}$} \\
\hline 28 & & \\
\hline 29 & $\begin{array}{c}\text { Trabalhos teóricos de recuperação do bimestre para os alunos } \\
\text { sem notas. Atividades esportivas livres para os demais. }\end{array}$ & $\begin{array}{l}\text { Prática/ } \\
\text { Teórica }\end{array}$ \\
\hline 30 & $\begin{array}{l}\text { Trabalhos teóricos de recuperação do bimestre para os alunos } \\
\text { sem notas. Atividades esportivas livres para os demais. }\end{array}$ & $\begin{array}{l}\text { Prática/ } \\
\text { Teórica }\end{array}$ \\
\hline
\end{tabular}

Fonte: Dados coletados pelo próprio autor. 
As observações das aulas tiveram início junto a introdução ao tema 2 do caderno do aluno, intitulado: "Corpo, saúde e beleza". Essa temática consta no currículo paulista e, recentemente, foi revisitada pela BNCC (BRASIL, 2018) como conteúdo integrante do currículo para o ensino médio. De acordo com o material disponibilizado pelo estado, nesta temática é possível apresentar que os estereótipos corporais da atualidade podem ser objetos de reflexão para uma a possível restruturação destes ou, ao menos, tornar esse assunto objeto de uma consciência voluntária por parte dos alunos, que muitas vezes reproduzem e têm esses estereótipos como algo verdadeiro e livre de questionamentos (COSTA; SILVA, 2014).

$\mathrm{Na}$ primeira aula observada, enquanto a professora apresentava o assunto, os alunos ficaram dispersos conversando, por isso, ela recorreu ao uso do apito em sala de aula para pedir a atenção deles, o fato causou estranheza e susto entre os presentes, mas a medida parece ter funcionado para 0 desenvolvimento das aulas da professora, que conseguiu, após realizar a verificação da frequência, a atenção do alunos e, assim, conduzir a aula teórica sobre o assunto "índice de massa corporal" relacionando-o ao tema mídia e beleza. A princípio, os alunos estavam apáticos e sem interesse, mas à medida que ela explicava e pedia exemplos para eles a aula foi tomando a atenção dos alunos, o que facilitou a comunicação entre professora e alunos. A partir dessa interação dinâmica estabelecida no decorrer da aula, possivelmente, aconteceu um vínculo que repercutiu positivamente no processo de ensino aprendizagem (RAMOS; GOETEN, 2015). A professora, próximo ao término dessa aula teórica pediu para os alunos, na aula da semana seguinte, trazer embalagens de comidas industrializadas que eles costumam consumir.

$\mathrm{Na}$ aula teórica seguinte, alguns alunos trouxeram as embalagens solicitadas, e conversaram sobre as calorias presentes nos alimentos que são consumidos e os níveis de açucares e sódio percebidos nas embalagens, a professora solicitou aos alunos que apresentassem, na aula seguinte, um trabalho sobre o consumo de açúcar e sal e em seguida os levou para a quadra da escola. Dessa forma, foi finalizada a atividade teórica, sem que existisse um diálogo entre a teoria e a prática e foi essa a dinâmica que perdurou a maior parte do tempo durante o período de observação, o que nos leva a perceber que não há uma relação direta entre a aula teórica e prática na disciplina.

Já que, frequentemente, as aulas teóricas de EF observada na coleta de dados, não estabeleceram um link com as práticas corporais desenvolvidas nas aulas práticas, nesse tempo de observação, a única vez que houve uma continuidade da teoria para prática foi com o tema frequência cardíaca. Uma vez que, o assunto foi explicado na sala de aula, a explanação contemplava a aferição da frequência em repouso, em seguida os alunos foram para a quadra e distribuídos em grupos, cada grupo realizou uma atividade, um grupo pulou corda, outro jogou tênis de mesa, outro jogou futebol, outro permaneceu sentado. Após dez minutos, todos verificaram suas frequências cardíacas e comentaram ao término da aula, em uma roda de conversa realizada na própria quadra, sobre como esta se modificou mediante a atividade desenvolvida. Esta foi uma atividade geradora de muita reclamação, pois, os alunos queriam realizar as atividades de costume, como jogar vôlei, futebol e tênis de mesa. 
Parte dos alunos, durante o período de observação, reclamaram da abordagem teórica utilizada nas aulas de Educação Física, mas, também, foi possível observar que eles reclamam das atividades práticas quando propostas e direcionadas pela professora. Apesar de serem participativos, eles costumam oferecer resistência ao planejamento da professora, seja ele, ligado ou não ao campo da saúde. Lidar com os alunos do Ensino Médio é uma atribuição, particularmente, complicada por este ser um momento da vida em que, normalmente, os alunos estão tomados por dúvidas, angústias e incertezas, sendo este um momento de intensas transformações e cabe ao professor ter sensibilidade e empatia para tentar os entender e assim, conseguir lidar com temas que são caros e necessários a esses discentes (DIAS, 2013; COSTA; SILVA, 2014).

Dessa forma, pode-se dizer, conforme a observação das aulas, que o conteúdo corpo e saúde que faz parte das aulas teóricas não encontra eco, além dessas aulas na disciplina. Também, chama a atenção o fato de não ser lembrado, nessas aulas, os aspectos sociais em que se encontra inserida a escola pesquisada e os alunos. Entretanto, pode-se perceber que existe um pensamento, no sentido, de refletir sobre possíveis mecanismos que permitam pensar no desenvolvimento de habilidades, sobretudo, no âmbito individual no que concerne aos elementos que influenciam positivamente na saúde. Contudo, Ihes são apresentados que desenvolver essas capacidades trata-se de "[...] uma opção individual e depende do esforço, da dedicação, da disciplina e dos cuidados de cada um/a para construí-lo" (FIGUEIRA, 2007, p. 126). Contudo, destaco que nas aulas sobre o tema "Corpo, saúde e beleza", os alunos levantaram muitas questões e tentaram responder com uma reflexão em conjunto, sobre os corpos que são vistos e apresentados a eles, mas que em muitas vezes não os representam.

Em meio as discussões sobre esse corpo, nas aulas teóricas de EF, foi possível perceber que este é um território em que emergem incertezas e inquietações. Pois, esse corpo está repleto de atribuições e necessidades, como apresentam Oliveira e Oliveira (2013) é divulgado em nossa sociedade que é imprescindível ser jovem, belo, magro, atlético, ativo, saudável, disposto, atualizado, atraente, estar na moda, com o corpo na moda. Outros estudiosos, também, trouxeram essa discussão para o campo da EF (RIBEIRO; MEZZAROBA, 2019; CASTRO et al., 2016; CHAVES et al., 2015; SILVA; SILVA; LÜDORF, 2015). Quando o corpo e a sua imagem são pensados além dos aspectos orgânicos e biológicos, é possível inferir, através das palavras de Ribeiro e Mezzaroba (2019), que o corpo é:

[...] um instrumento de uma cultura líquida e consumista que valoriza o prazer rápido, resultados adiposidade e muscularidade na Educação Fìsica e na Nutrição imediatos e receitas já comprovadas de sucesso. O corpo tornou-se uma mercadoria que é trocada a todo momento, com o objetivo de estar sempre atualizado, na moda. A paciência e a incerteza são diminuídas - ou eliminadas - para que a imagem do corpo seja atlética e jovial (RIBEIRO; MEZZAROBA, 2019, p. 812). 
Percebe-se que este é um assunto que cabe, ainda, reflexões. Pois, esse padrão corporal que é amplamente divulgado, juntamente aos benefícios e sacrifícios contemplam toda sociedade. E na escola esse fenômeno, como mostra esse estudo, também foi observado. Contudo, destaco que quando se trata da teoria dos assuntos relacionados a saúde e abordados nas aulas teóricas de Educação Física, e aqui acentuo o assunto abordado dentro da unidade "padrões corporais", é reconhecido que as preocupações recaem de forma mais intensa sobre as meninas, como nos lembra Figueira (2007, p. 132) é desejável que "[...] cada garota deve aprender a cuidar de sua saúde, a se responsabilizar pelo seu embelezamento e pelo próprio bem-estar". Os alunos reconheceram essa cobrança maior em relação as meninas durante uma aula teórica, como lê-se a seguir: "Um monte de meninas fica mal sendo que aquela pessoa nem existe, é tudo virtual ou fotoshop" (ALUNO BERNARDO); e "[...] tem uma pá de youtuber falando de dieta, exercício e fazendo propaganda na internet. Falando o que as meninas precisam fazer" (ALUNA MAURA).

Outros estudos revelam essa "orientação cultural espontânea" às mulheres da necessidade de ser bela conforme os padrões vigentes de beleza (LOPES; ANDRADE, 2017; DIAS, 2013; CAMPOS; CECÍLIO; PENAFORTE, 2016). Goldenberg (2005) reporta que os corpos femininos reputam o império dos discursos da boa forma de maneira mais cruel. Nesse sentido, o corpo feminino, pode-se dizer, é carregado de um discurso consensual e atual de beleza fundamentado na imagem do corpo magro, atlético, que por vezes é associado ao sucesso e felicidade desde a adolescência (FIGUEIRA, 2007).

Chama a atenção o desejo dos alunos em ter o horário da aula de EF na quadra. No entanto, foi observado que a maciça e presente atuação dos alunos nas aulas teóricas não se repetiu nas aulas práticas, nessas aulas, muitos alunos não participavam ou participavam em alguns momentos ou dias específicos. Percebe-se que a participação irregular dos alunos nas aulas de EF no ensino médio não é uma dinâmica recente ou inesperada como apontam outros estudos (PEREIRA; MOREIRA, 2005; HINO; REIS; AÑEZ, 2007; LORENZ; TIBEAU, 2003; ALMEIDA; CAUDURO, 2007).

Assim como, também, é comum que a maior participação nas aulas práticas de EF seja dos meninos. Na turma observada acontecia uma separação da sala em grupos distintos, um grupo de meninos com cerca de dez alunos dominava, normalmente, a quadra com partidas de futsal, um outro grupo misto utilizava um espaço aberto ao lado da quadra para atividades como vôlei e tênis de mesa, e um terceiro grupo composto só por meninas pegavam colchonetes e passavam o tempo de aula sentadas no chão fazendo maquiagem ou utilizando o celular. Normalmente, o grupo que realizava atividades diversas fora da quadra coberta, nos dias de chuva se reunia junto das alunas que não participavam das aulas em um hall que antecede a quadra, e, como elas - as não praticantes, ficavam esperando o tempo destinado a aula de EF passar com conversas e utilizando o telefone celular. Tal observação se assemelha, em parte, ao encontrado por Oliveira e Daolio (2014), principalmente, na observação de dois tipos de grupos de alunos em relação as suas participações nas aulas práticas, os ativos e os (im) praticantes. De acordo com Oliveira e Daolio (2014), são expostas três categorias de análise da participação e 
apropriação da aula de EF por alunos que se encontravam à margem dela, a saber: "pedacinho" (im)praticante, "pedacinho" ativo e "pedacinho flutuante". O primeiro reunia alunas que não se envolviam com as aulas, usufruindo o tempo para outras coisas; o segundo "pedacinho" era composto por um grupo sempre pronto às atividades, mas também com grave apelo ao futebol; por fim, o flutuante era um grupo que se encontrava na fronteira entre os dois grupos anteriores.

Portanto, foi possível verificar que o uso do principal espaço destinado as aulas - a quadra, e as práticas corporais que lá aconteciam são vulneráveis as diferenças de gênero, assim como declarou González-Palomares, Altmann e ReyCao (2015). Se nas discussões estabelecidas nas aulas teóricas os temas relacionados ao corpo e saúde pareceram incidir de modo mais intenso sobre as meninas, nas aulas práticas o espaço privilegiado de prática foi de domínio masculino, outros estudos tiveram constatações parecidas quanto a apropriação dos espaços reservados as aulas de EF (ALTMANN, 1998; WENETZ; STIGGER, 2006).

Por isso, gostaria de pontuar, apesar de não ser o objetivo do estudo, que é possível observar que há certa invisibilidade para as meninas no que concerne as práticas corporais, sobretudo, ao esporte, uma vez que os espaços e atividades são dominados pelos rapazes da turma, a elas cabe um papel de coadjuvantes ou convidadas, sem fazer jus ao espaço principal e as práticas corporais que foram voltadas para os meninos. Ainda, no que compete ao âmbito das aulas práticas, os resultados das observações indicam que as atividades dessas aulas, embora não fossem conduzidas pela professora de Educação Física, na maior parte do tempo, os esportes foram as práticas privilegiadas, sobretudo, a modalidade de futsal. O futsal foi o esporte priorizado, tanto pela frequência que aconteceu, apenas em duas aulas práticas, dentre as observadas ele não foi realizado, e, também, com o espaço da quadra coberta, mesmo a modalidade não reunindo a maior parte dos alunos da sala e só participando os meninos. A limitação de repertório nas aulas práticas de Educação Física, provavelmente, impacta no desenvolvimento das atividades práticas, pois observou-se, assim como Oliveira e Daolio (2014) constataram, que as atividades realizadas na escola privilegiam o esporte, sobretudo, o futebol e isso acontece de forma a excluir, principalmente, as meninas. Os autores aprofundam essa questão ao declararem que os alunos:

[...] continuaram reféns de um conhecimento limitado, no que se refere às práticas corporais, que, deixadas de lado nas aulas de EF, cederam espaço para toda e qualquer influência estereotipada advinda de outras instituições, como, por exemplo, a mídia, que valoriza a competição e o rendimento esportivo, em detrimento das outras manifestações corporais (OLIVEIRA; DAOLIO, 2014, p. 244).

Portanto, embora nesses momentos ou aulas livres sejam realizados pela maior parte dos alunos alguma atividade esportiva, o que fica em evidência é a socialização e a brincadeira entre amigos. Não existe um objetivo específico ou um planejamento para essas atividades que contemple a saúde, pelo menos, 
não dentro da perspectiva ampliada como a apresentada por Minayo (1997), na qual expressa a saúde além de aspectos biológicos, devendo a pessoa ser considerado integralmente.

A partir das aulas observadas, foi possível perceber que a professora de EF trabalha, rotineiramente, a temática saúde. No entanto, esse trabalho centrase em uma perspectiva de autocuidado baseada no fomento da saúde. Nas aulas, os alunos tiveram uma amostra de que praticar atividades físicas e se alimentar bem são suficientes para manter uma boa saúde. Não se trata de fazer uma crítica ao formato das aulas adotados durante a observação, não se pretende aqui dizer que este é um formato incorreto de conduzir as aulas de EF. Pois, como nos lembram Carvalho e Mendes (2019, p. 23), "[...] a saúde é um conceito político e complexo porque nos remete a muitas possibilidades e, ao mesmo tempo, não diz efetivamente quase nada a respeito da saúde". No entanto, reconhecemos que esse espaço de prática pode ser importante para que os alunos percebam que corpo, EF e saúde podem estar concatenados e, ainda, serem frutos de uma sociedade e não apenas um resultado individual. Por isso, a necessidade de compreender o corpo além de uma perspectiva biológica, pensando nele, conforme aponta Herold Júnior (2017), como um ser social e a EF como uma via de geração de reflexões observando suas dimensões históricas e sociais.

Além da priorização dos aspectos biológicos contemplados nas aulas teóricas, foi possível constatar, nessa observação, que os conteúdos existentes no caderno do aluno e desenvolvidos nesse momento, embora, num primeiro momento, não fossem bem aceitos, estes geraram nos alunos interesse. Acredito que isso aconteça por nessas aulas ser possível discutir assuntos que os possibilitam falar de temas em que existe uma certa passividade da sociedade e são por vezes velados. A teoria encontrada no material disponibilizado pelo Estado e utilizada no início do bloco de aulas, normalmente, com o decorrer das discussões fomentadas pela professora, que assume nas aulas teóricas uma posição de autoridade conduzindo inteiramente as atividades, toda a sala participa das atividades propostas neste momento da aula e tendem a refletir sobre alguns assuntos importantes relacionados a saúde e ao corpo, mesmo que essa discussão não permeie, na maior parte do tempo, um viés de saúde ampliada na perspectiva de Minayo (1997).

Entretanto, as aulas na quadra, as aulas práticas, não seguem essa tendência de participação. Embora, exista uma solicitação da professora para que todos alunos realizem alguma atividade prática é perceptível que a aula não é pensada para todos. Esse fato pode ser resultado da falta de materiais pedagógicos e/ou falta de estrutura física na escola para que aconteçam aulas com mais participação, a repetição do formato de aulas com as mesmas atividades durante o ano letivo ou, ainda, podemos pensar na indiferença da professora em relação a apatia da maior parte dos alunos nas aulas práticas. Embora, nas discussões realizadas na sala, as opiniões mostradas sejam da necessidade da prática de EF para fins de saúde. 


\section{Considerações finais}

Percebe-se que as aulas de EF realizadas na escola observada possui um formato que contempla aspectos relacionados a saúde. Esse direcionamento das aulas às questões da saúde trata-se, provavelmente, de um reflexo do currículo do estado de São Paulo que, por meio do Caderno do Aluno, apresentam conteúdos que favorecem a abordagem e discussão desse tema. Contudo, é perceptível que esses assuntos contribuem, principalmente, nos aspectos físicos e biológicos, conferindo aos alunos um direcionamento para uma responsabilidade de caráter individual no que tange a ter saúde. Além disso, demostrando vestígios que a saúde se pauta em uma aparente relação de dependência entre o exercício físico e a promoção desta.

Por isso, ressaltamos a necessidade de se reinterpretar o cenário composto pela EF e o tema saúde. Nesse sentido, pensamos na possibilidade de se aprofundar na escola os temas existentes e abordados nas aulas de EF, mas considerando e fundamentando a saúde sob a ótica de um conceito ampliado que considere o ser humano no todo, inclusive, em seu contexto social. Para isso, torna-se necessário repensar o formato das aulas para que estas tenham continuidade e significado para os alunos, trazendo para as aulas de EF uma perspectiva de saúde que possa propiciar o protagonismo desses alunos frente as questões que estão presentes em suas realidades de vida, considerando, no âmbito escolar, que as aulas de EF podem ir além da prática de atividades físicas. Para mais além, participar da construção de um ideal de promoção de saúde centrado na integralidade humana.

Em síntese, a reflexão aqui desenvolvida sinaliza que a EF escolar possui um lugar privilegiado de abordagem dos temas corpo e saúde no ensino médio. Contudo, ainda com amarras às Ciências Naturais, que, não raramente, sustentada pelo discurso "faça atividade física e seja saudável", impõem limitações à reflexão dos alunos no horizonte da cultura corporal. Entretanto, os resultados aqui devem ser lidos com cautela, menos na direção de uma teorização engessada e mais na direção de uma argumentação sustentada a partir de dados oriundos de um contexto particular. Isso não significa a invalidade do esforço interpretativo. Em etnografia, são nas particularidades que as interpretações ganham sentido e permitem as generalizações (FONSECA, 1999). Todavia, chega-se ao fim deste estudo com possibilidade de avançar sobre as questões discutidas, especialmente no que se refere a relevância de se pensar no corpo e saúde em uma perspectiva ampla, tendo como ponto de partida o papel das práticas corporais no Ensino Médio.

\section{REFERÊNCIAS}

ALMEIDA, Pedro Cesár; CAUDURO, Maria Teresa. O desinteresse pela Educação Física no ensino médio. Lecturas, Educación Fisica y Deportes, Buenos Aires, v. 11, n. 106, p. 1-11, 2007. 
ALTMANN, Helena. Rompendo fronteiras de gênero: Marias (e) homens na Educação Física. 110 f. Dissertação (Mestrado em Educação) - Faculdade de Educação, Universidade Federal de Minas Gerais, Belo Horizonte, 1998.

BARDIN, Laurence. Análise de Conteúdo. Lisboa: Edições 70, 1977.

BETTI, Mauro. Ensino de primeiro e segundo graus: Educação Física para quê? Revista Brasileira de Ciências do Esporte, Maringá, v. 13, n. 2, p. 282287, 1992.

BETTI, Mauro; ZULIANI, Luiz Roberto. Educação física escolar: uma proposta de diretrizes pedagógicas. Revista Mackenzie de Educação Física e Esporte, Barueri, v. 1, n. 1, p. 73-81, 2002.

BRACHT, Valter. A constituição das teorias pedagógicas da educação física. Cadernos CEDES, Campinas, v. 19, n. 48, p. 69-88, 1999.

BRASIL. Base Nacional Comum Curricular (BNCC). Educação é a Base. Ensino Médio. Brasília: MEC/CONSED/UNDIME, 2018.

CAMPOS, Claudinei José Gomes. Método de análise de conteúdo: ferramenta para a análise de dados qualitativos no campo da saúde. Revista Brasileira de Enfermagem, Brasília, v. 57, n. 5, p. 611-614, 2004.

CAMPOS, Maria Teresa de Assis; CECÍLIO, Mariana Silva; PENAFORTE, Fernanda Rodrigues. Corpo-vitrine, ser mulher e saúde: produção de sentidos nas capas da revista boa forma. DEMETRA: Alimentação, Nutrição \& Saúde, Rio de Janeiro, v.11, n. 3, p. 611-628, 2016.

CARRANO, Paulo. Identidades culturais e escolas: arenas de conflitos e possibilidades. In: MOREIRA, Antônio Flávio; CANDAU, Vera Maria (Orgs.). Multiculturalismo: diferenças culturais e práticas pedagógicas. 7.ed. Petrópolis: Vozes, 2011. p. 182-211.

CARVALHO, Yara Maria; MENDES, Valéria Monteiro. Corpo e cuidado: as práticas corporais como práticas de cuidado em saúde: provocações. São Paulo: Hucitec, 2019.

CASTRO, Juliana Brandão Pinto de; MATTOS, Rafael da Silva; PASSOS, Michelle Delboni dos; AQUINO, Fernanda Silva Dias de; RETONDAR, Jeferson José Moebus; MACHADO, Anderson dos Santos. Alimentação, corpo e subjetividades na efe na nutrição: o ranço da adiposidade e a ascensão dos músculos. DEMETRA: Alimentação, Nutrição \& Saúde, Rio de Janeiro, v. 11, n. 3, p. 803-824, 2016.

CHAVES, Paula Nunes; BARROS, Joyce Mariana Alves; SOUSA, Dandara Queiroga de Oliveira, COSTA, Ana Luiza Silva; ARAÚJO, Allyson Carvalho de. 
Construindo diálogos entre a mídia-educação e a Educação Física: uma experiência na escola. Motrivivência, Florianópolis, v. 27, n. 44, p. 150-163, 2015.

CORREIA, Walter Roberto. Educação Física no ensino médio: questões impertinentes. 2.ed. Várzea Paulista: Fontoura, 2011.

COSTA, Naiana Thaíssa Menezes; SILVA, Alan Camargo. Corpo e Educação Física escolar no ensino médio: a visão dos alunos. Revista Brasileira de Ciências Esporte, Florianópolis, v. 36, n. 2 (supl.), p. 223-237, 2014.

DAOLIO, Jocimar. Consequências do conceito de cultura para a educação física escolar. In: PACHECO NETO, Manuel (Org.). Desafios da educação física: cultura e corpo em movimento. Dourados: UFGD, 2016. p. 57-73.

DAOLIO, Jocimar. Da cultura do corpo. Campinas: Papirus, 1995.

DEVIDE, Fabiano Pries. Educação Física e saúde: em busca de uma reorientação para a sua práxis. Movimento, Porto Alegre, v. 3, n. 5, p. 44-55, 2007.

DIAS, Juliana Rocha Adelino. Culturas escolares e adolescentes: Imagem corporal e relações sociais. 2013. 222f. Dissertação (Mestrado em Educação) Universidade Católica de Santos, Santos, 2013.

FIGUEIRA, Maria Machado. A revista capricho e a produção de corpos adolescentes femininos. In: LOURO, Guacira Lopes; FELIPE, Jane; GOELLNER, Silvana Vilodre (Orgs.). Corpo, gênero e sexualidade: um debate contemporâneo na educação. 3. ed. Petrópolis: Vozes, 2007. p. 124-135.

FONSECA, Claudia. Quando cada caso não é um caso: pesquisa etnográfica e educação. Revista Brasileira de Educação, Rio de Janeiro, s/v, n. 10, p. 5878, 1999.

GEERTZ, Clifford. A interpretação das culturas. Rio de Janeiro: LTC, 1989.

GOELLNER, Silvana Vilodre. Educação física, ciência e saúde: notas sobre o acervo do Centro de Memória do Esporte (UFRGS). História, Ciências, Saúde-Manguinhos, Rio de Janeiro, v. 7, n. 2, p. 527-536, 2010.

GOELLNER, Silvana Vilodre. A produção cultural do corpo. In: LOURO, Guacira Lopes; FELIPE, Jane; GOELLNER, Silvana Vilodre (Orgs.). Corpo, gênero e sexualidade: um debate contemporâneo na educação. 3.ed. Petrópolis: Vozes, 2007, p. $124-135$.

GOLDENBERG, Mirian. A arte de pesquisar: como fazer pesquisa qualitativa em ciências sociais.10.ed. Rio de Janeiro: Record, 2007. 
GOLDENBERG, Mirian. Gênero e corpo na cultura brasileira. Psicologia Clínica, Rio de Janeiro, v. 17, n. 2, p. 65-80, 2005.

GONÇALVES, Andreia Santos; AZEVEDO, Aldo Antônio de. A re-significação do corpo pela Educação Física escolar, face ao estereótipo de corpo ideal construído na contemporaneidade. Pensar a Prática, Goiânia, v. 10, n. 2, p. 33-51, 2007.

GONZÁLEZ-PALOMARES, Alba; ALTMANN, Helena; REY-CAO, Ana. Estereótipos de gênero nas imagens dos livros didáticos de educação física do brasil.

Movimento, Porto Alegre, v. 21, n. 1, p. 219-232, 2015.

HEROLD JÚNIOR, Carlos. Avaliar As práticas corporais no campo da saúde: o que podem os diálogos entre Educação Física e saúde coletiva. Revista Brasileira de Ciências do Esporte, Porto Alegre, v.39, n. 4, p. 458-460, 2017.

HINO, Adriano Akira Ferreira; REIS, Rodrigo Siqueira; AÑEZ, Ciro Romélio Rodriguez. Observação dos níveis de atividade física, contexto das aulas e comportamento do professor em aulas de Educação Física do ensino médio da rede pública. Revista Brasileira de Atividade Física \& Saúde, Pelotas, v. 12, n. 3, p. 21-30, 2007.

LOPES, Michelle Aparecida Pereira; ANDRADE, Gabriela Vilela. O "corpo perfeito" na revista boa forma: o discurso didatizado que objetiva e subjetiva. Ciência ET Praxis, Passos, v. 10, n. 19, p. 71-75, 2017.

LORENZ, Camila; TIBEAU, Cynthia. Educação física no ensino médio: estudo exploratório sobre os conteúdos teóricos. Lecturas, Educación Fisica y Deportes, Buenos Aires, v. 9, n. 66, p. 1-11, 2003.

LOURO, Guacira Lopes. Corpo, Escola e Identidade. Educação \& Realidade, Porto Alegre, v. 25, n. 2, p. 59-75, 2000.

LÜDORF, Sílvia Maria Agatti. Corpo e formação de professores de educação física. Interface, Botucatu, v. 13, n. 28, p. 99-110, 2009.

MAGNANI, José Guilherme Cantor. De perto e de dentro: notas para uma antropologia urbana. Revista Brasileira de Ciências Sociais, São Paulo, v. 17, n. 49, p. 11-29, 2002.

MINAYO, Maria Cecília de Souza. Saúde: concepções e políticas públicas. Saúde e doença como expressão cultural. In: AMÂNCIO FILHO, Antenor; MOREIRA, Maria Cecilia Gomes Barbosa (Orgs.). Saúde, trabalho e formação profissional. Rio de Janeiro: Fiocruz, 1997. p. 31-49. 
MOREIRA, Daniel Augusto. O método fenomenológico na pesquisa. São Paulo: Pioneira Thomson, 2002.

OLIVEIRA, Flavia; OLIVEIRA, Rogério Cruz. O culto ao corpo e seus desdobramentos contemporâneos. Lecturas, Educación Fisica y Deportes, Buenos Aires, v. 18, n. 185, p. 1-11, 2013.

OLIVEIRA, Rogério Cruz; DAOLIO, Jocimar. Na "periferia" da quadra: Educação Física, cultura e sociabilidade na escola. Pro-Posições, Campinas, v. 25, n. 2, p. 237-254, 2014.

OLIVEIRA, Rogério Cruz.; DAOLIO, Jocimar. Pesquisa etnográfica em Educação Física: uma (re)leitura possível. Revista Brasileira de Ciência e Movimento, Brasília, v. 15, n. 1, p. 137-143, 2007.

OLIVEIRA, Victor José Machado de; GOMES, Ivan Marcelo; BRACHT, Valter. Educação para a saúde na educação física escolar: uma questão pedagógica! Cadernos de Formação da RBCE, Porto Alegre, v. 5, n. 2, p. 68-79, 2014.

PAULA, Eliana de Jesus de; PAIXÃO, Jairo Antônio; OLIVEIRA, Emerson Cruz. Suspensão de aulas de Educação Física como forma de punição: a percepção discente. Pensar a Prática, Goiânia, v. 18, n. 2, p. 461-471, 2015.

PEREIRA, Raquel Stoilov, MOREIRA, Evando Carlos. A participação dos alunos do ensino médio em aulas de Educação Física: algumas considerações.

Revista da Educação Física - UEM, v. 16, n. 2, p. 121-127, 2005.

RAMOS, Daniela Karine; GOETEN, Ana Paula Moreira. Aspectos motivacionais e a relação professor-aluno: um estudo com alunos do ensino. CAMINE:

Caminhos da Educação, Franca, v. 7, n. 1, p. 23-37, 2015.

RIBEIRO, Sérgio Dorenski Dantas; MEZZAROBA, Cristiano. Mídia, corpo e mercado: (im)possibilidades formativas diante do poder simbólico.

Perspectiva, Florianópolis, v. 37, n. 1, p.160-183, 2019.

SILVA, Fernanda Azevedo Gomes da; SILVA, Luis Aureliano Imbiriba ;LÜDORF, Sílvia Maria Agatti. Concepções de corpo e a prática pedagógica de professores de Educação Física do ensino médio. Pensar a Prática, Goiânia, v. 18, n. 2, p. 41-57, 2015.

WENETZ, Ileana; STIGGER, Marco Paulo. A Construção do Gênero no Espaço Escolar. Movimento, Porto Alegre, v. 12, n. 1, p. 59-80, 2007.

Recebido em: 10 de novembro de 2020. Aceito em: 10 de maio de 2021. Publicado em: 30 de junho de 2021. 